\title{
Patients' Commitment to Their Primary Physician and Why It Matters
}

\author{
Leonard L. Berry, PbD \\ Janet Turner Parish, PbD ${ }^{2}$ \\ Ramkumar Janakiraman, $P b D^{1}$ \\ Lee Ogburn-Russell, PbD, RN ${ }^{3}$ \\ Glen R. Coucbman, $M D^{3}$ \\ William L. Rayburn, MD \\ Jedidiab Grisel, $M D^{5}$ \\ 'Mays Business School, Texas A\&M \\ University, College Station \\ ${ }^{2} \mathrm{McC}$ Coy College of Business Administra- \\ tion, Texas State University, San Marcos \\ ${ }^{3}$ Scott and White, Texas A\&M University \\ Health Science Center, Temple \\ ${ }^{4}$ Scott and White Clinic, Texas A\&M \\ University Health Science Center, \\ College Station \\ ${ }^{5}$ University of Cincinnati Medical Center, \\ Cincinnati, Ohio
}

\begin{abstract}
PURPOSE The patient-physician relationship is the cornerstone of health care service delivery. The objectives of this study were to assess the contribution of relationship commitment along with trust to patient-physician relationships and to evaluate the association of commitment and trust with adherence to medical advice and healthy eating behaviors.

METHODS To test the proposed model, we developed a questionnaire that included both existing scales and a scale constructed specifically for the study; the questions addressed trust, commitment, adherence to physicians' medical recommendations, and healthy eating behavior. The questionnaire was given to adult patients in the waiting rooms of 4 large clinics in central Texas.
\end{abstract}

RESULTS A total of 1,008 patients returned questionnaires; 869 patients' questionnaires were complete and used in the analysis. A 3-stage least squares analysis that tested a system of 4 equations which included relationship commitment yielded a systemwide $R^{2}$ of 0.71 that was 0.09 higher than a system of equations excluding relationship commitment. Trust and commitment were positively associated with adherence $(P<.001$ and $P=.02$, respectively). We also found positive relationships between adherence and commitment and between trust and commitment $(P<.001$ for each). Adherence and commitment were both associated with healthy eating behavior as well $(P<.001$ for each).

CONCLUSIONS Patients' trust in their physician and commitment to the relationship offer a more complete understanding of the patient-physician relationship. In addition, trust and commitment favorably influence patients' health behaviors.

Ann Fam Med 2008;6:6-13. DOI: 10.1370/afm.757.

\section{INTRODUCTION}

$\mathrm{T}$ The intimacy, importance, complexity, and variability of medical services cause many patients to desire continuity with 1 physician as a primary source of care. Safran ${ }^{1}$ has summarized a series of studies in the United States starting in the 1970s indicating that most adults have a physician they consider to be their primary physician. The percentages reported range from $88 \%$ in 1975 to $77 \%$ in $1996 . .^{2-5}$ In 2005 , $76 \%$ of 35,383 patients studied reported that they saw the same clinician always or most of the time. ${ }^{6}$ This figure is similar to the $68.3 \%$ of 16,435 patients that a group of primary care physicians identified from their patient panel as being their patients. ${ }^{7}$ A study of family practice patients in the United States and United Kingdom found that $79 \%$ of patients rated seeing the same physician for a health problem as important or very important. ${ }^{8}$ Fan et $a l^{6}$ found that those patients who reported seeing the same physician always or most of the time had patient satisfaction scores that were significantly higher than those of their counterparts who did not see the same physician. Clearly, most patients value continuity of care. Learning more about the patient-physician relationship motivated our study. We wanted to investigate whether strength of the patientphysician relationship was associated with positive patient attitudes and
Leonard L. Berry, PhD M.B. Zale Chair in Retailing and Marketing Leadership Department of Marketing Mays Business School Texas A\&M University College Station, TX 77843-4112 BerryLe@tamu.edu

Conflicts of interest: none reported

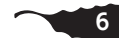


behaviors (ie, adherence to medical recommendations and healthy eating).

In general, patients remain in relationships with clinicians either by choice or because they perceive no alternative. The former can be termed dedication-based relationships; the latter, constraint-based relationships. ${ }^{9}$ For various reasons, including insurance plan design, unavailability of substitute clinicians, or patient passivity, patients may remain with physicians even when they do not want to; however, one should expect the patientphysician relationship to differ qualitatively based on why the patient maintains it. Accordingly, in this study, we distinguish between duration of care and patient commitment to the relationship. Relationship commitment is the degree to which a relationship is valued; with commitment, the patient wants the relationship to continue and invests energy toward its continuance.

Trust is considered a key component of relationships between patients and physicians. ${ }^{10-12}$ Trust exists when patients perceive their physician to be sincere, credible, honest, and benevolent. ${ }^{13,14}$ Trust can lead to important outcomes. For example, patients' trust in their physician has been shown to predict patient satisfaction $^{8}$ and adherence to a medical regimen. ${ }^{15}$ A study of hypertensive patients' adherence to medication recommendations found that patients with the lowest levels of adherence do not trust their physicians. ${ }^{16}$ Yet, other research suggests that, depending on the method of analysis, there may be no "physician effect" (which includes trust) on patient outcomes. ${ }^{17}$

We explored the patient-physician relationship by including relationship commitment in our evaluation and specifically measuring its effects. We believe that trust strengthens relationship commitment, and measuring both constructs together could improve our understanding of patient-physician relationships. Morgan and Hunt ${ }^{18}$ hold that both trust and commitment are key to all commercial relationships. Such a conclusion should be no less true for the delivery of primary care health services. We therefore designed our study to explore the association of trust and relationship commitment with 2 desirable patient outcomes: medical adherence and healthy eating. We also wanted to learn more about the antecedents of strong patient-physician relationships, specifically, the antecedents of trust.

Primary care physicians play a key role in encouraging adherence to prescribed medical regimens and healthy lifestyles. ${ }^{15,19-23}$ Adherence is a salient issue. A meta-analysis of 63 studies assessing patient adherence and medical treatment outcomes concluded that, on average, $26 \%$ more patients had a good outcome through adherence vs nonadherence. ${ }^{24}$ Yet, research shows that patient adherence in taking prescribed medications is suboptimal, with little relation to social and demographic characteristics. ${ }^{23-27}$ A systematic review of published randomized controlled trials of interventions to increase patients' adherence to prescribed medications showed that even the most effective interventions did not lead to large improvements in adherence and treatment outcomes. ${ }^{28}$ We conceptualize adherence as an attitude toward following physician suggestions; therefore, in our model, adherence is a mediator between trust and healthy eating behaviors.

We selected healthy eating behaviors for study because of the alarming rise of obesity in America and obesity's role as a well-known risk factor for multiple diseases, including hypertension, type 2 diabetes, osteoarthritis, cardiovascular disease, stroke, certain types of cancer, and dementia. ${ }^{29-33}$ Any association between strength of the patient-physician relationship and patients' healthy eating behavior would merit further attention and research.

The model that we tested (Figure 1) posits that patients' trust of their physician is associated with 3 composite physician behaviors: developing knowledge of the patient, demonstrating medical competence, and supporting patient autonomy. ${ }^{17,34,35}$ Knowledge of the patient refers to patients' perceptions that their physician knows their medical history and knows them as a person. Competence is defined as the degree to which

\section{Figure 1. Conceptual diagram of proposed model relationships.}

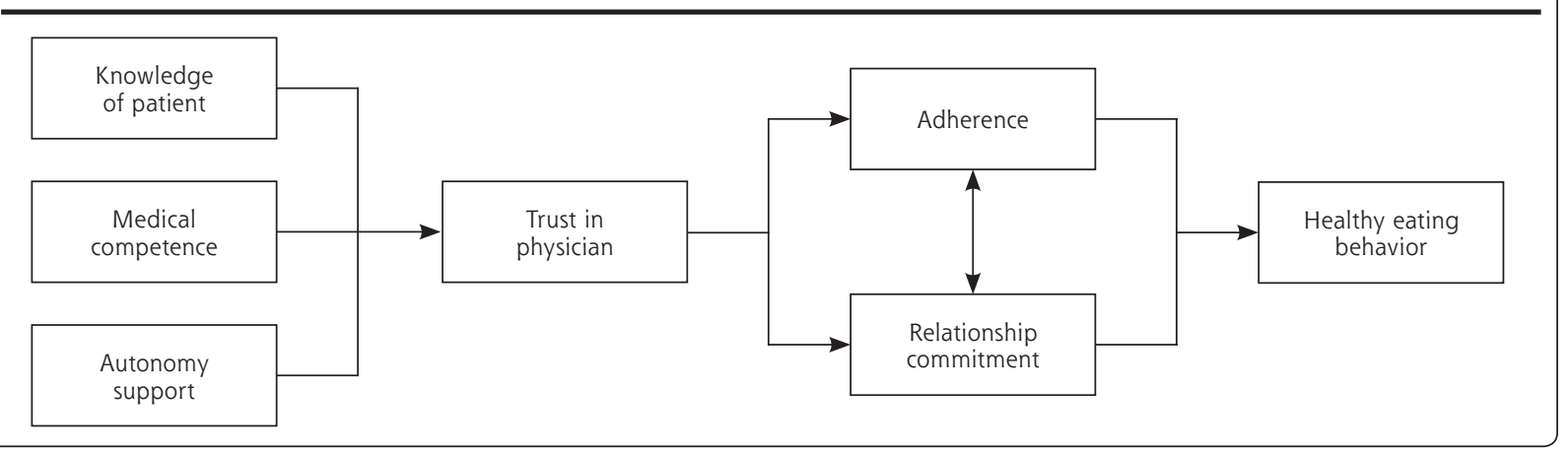

ANNALS OF FAMILY MEDICINE + WWW.ANNFAMMED.ORG + VOL. 6, NO. 1 + JANUARY/FEBRUARY 2008 
patients perceive that physicians have the skills and knowledge required to provide for their health care needs. ${ }^{36}$ Patient autonomy refers to patients' perceptions that their physician encourages questions and listens to their requests. ${ }^{37}$ We postulated that patients' commitment to their relationship with their physician is linked to their trust perceptions. We also posited that both trust and commitment influence adherence to medical recommendations. We further hypothesized that commitment and adherence are associated and both contribute to healthy eating behaviors. Patients' trust in and commitment to their primary physician are thus instrumental in improving adherence and diet.

\section{METHODS} Questionnaire

To test the proposed model, we developed a questionnaire that included existing scales that were adapted for this study and a new scale for competence. The scales, as well as their sources, means, reliabilities, and items are displayed in Table 1 . We measured attitudinal commitment (eg, "The relationship ... is important to $\left.\mathrm{me}^{\prime \prime}\right)$. We pretested and refined our questionnaire in several phases. First, we convened a group of 10 adults to complete the questionnaire and then provide feedback on instructions or questions that were problematic. We then mailed a revised questionnaire with a

\section{Table 1. Measures, Sources, Means, Reliabilities ( $\alpha$ ), and Items}

\begin{tabular}{|c|c|c|c|c|}
\hline Measure & Source & Mean & $\alpha$ & Items $^{a}$ \\
\hline Knowledge of patient & $\begin{array}{l}\text { Primary Care } \\
\text { Assessment Survey }\end{array}$ & 5.91 & .903 & $\begin{array}{l}\text { My doctor knows my medical history well. } \\
\text { My doctor knows what worries me the most about my health. } \\
\text { My doctor knows about me as a person, he/she knows my values. }\end{array}$ \\
\hline Competence & New items & 6.72 & .953 & $\begin{array}{l}\text { My doctor is competent. } \\
\text { My doctor is knowledgeable about current medical procedures } \\
\text { and treatments. } \\
\text { My doctor knows the best way to treat his/her patients' conditions. } \\
\text { My doctor is an excellent source of accurate information. }\end{array}$ \\
\hline Autonomy support & $\begin{array}{l}\text { Health Care Climate } \\
\text { Questionnaire }\end{array}$ & 6.13 & .920 & $\begin{array}{l}\text { I feel understood by my doctor. } \\
\text { My doctor conveys confidence in my ability to make changes. } \\
\text { My doctor encourages me to ask questions. } \\
\text { My doctor listens to how I would like to do things. }\end{array}$ \\
\hline Trust in physician & $\begin{array}{l}\text { Primary Care } \\
\text { Assessment Survey }{ }^{38}\end{array}$ & 6.58 & .912 & $\begin{array}{l}\text { I can tell my doctor anything. } \\
\text { I completely trust my doctor's judgment about my medical care. } \\
\text { My doctor would always tell me the truth about my health, } \\
\text { even if there were bad news. } \\
\text { My doctor cares about my health. }\end{array}$ \\
\hline Adherence & $\begin{array}{l}\text { General Adherence } \\
\text { Scale }^{20}\end{array}$ & 4.94 & .945 & $\begin{array}{l}\text { I find it easy to do the things that my doctor suggests. } \\
\text { I am able to do what is necessary to follow my doctor's advice. } \\
\text { I follow my doctor's suggestions. } \\
\text { I am usually willing to do what my doctor advises me to do. }\end{array}$ \\
\hline Relationship commitment & Morgan and Hunt ${ }^{18}$ & 6.29 & .961 & $\begin{array}{l}\text { The relationship that I have with my doctor is ... } \\
\text { Something I am committed to. } \\
\text { Important to me. } \\
\text { Something I intend to maintain indefinitely. } \\
\text { Something I care about. } \\
\text { Worth the effort to maintain. }\end{array}$ \\
\hline Healthy eating behaviora & Glasgow et $\mathrm{al}^{39}$ & NA & NA & $\begin{array}{l}\text { How many times a week do you eat fast food? } \\
\text { How many servings of fruit or vegetables do you eat each day? } \\
\text { How many times a week do you eat beans (like pinto or black } \\
\text { beans), chicken, or fish? } \\
\text { How many times a week do you eat regular chips or crackers } \\
\text { (not low fat)? } \\
\text { How many times a week do you eat desserts or other sweets? }\end{array}$ \\
\hline Presence of chronic illness ${ }^{a}$ & New item & NA & NA & $\begin{array}{l}\text { Are you currently under the care of a doctor for a chronic illness } \\
\text { such as diabetes, heart disease, or asthma? }\end{array}$ \\
\hline \multicolumn{5}{|l|}{ NA $=$ not applicable. } \\
\hline $\begin{array}{l}\text { a All measures other than health } \\
\text { strongly agree ( } 7) \text { as the anchor } \\
\text { dropped from the analysis if the } \\
\text { for presence of chronic illness w }\end{array}$ & $\begin{array}{l}\text { esponse options for heal } \\
\text { pondent chose the don't } \\
\text { yes and no. }\end{array}$ & $\begin{array}{l}\text { of chro } \\
\text { ating b } \\
\text { /not s }\end{array}$ & $\begin{array}{l}\text { ess } \\
\text { r we } \\
\text { tion }\end{array}$ & $\begin{array}{l}\text { assessed with multi-item, } 7 \text {-point Likert scales with strongly disagree ( } 1 \text { ) and } \\
\text { one, } 1 \text { time, } 2 \text { times, } 3 \text { or more times, and don't know/not sure (a response wa } \\
\text { e were } 139 \text { such responses out of a total 1,008 responses). Response options }\end{array}$ \\
\hline
\end{tabular}


cover letter on a test basis to a random sample of 750 adults living in a 5-county area in the central United States. We received 93 completed questionnaires and further revised the questionnaire based on the results of exploratory factor analysis and reliability analysis.

\section{Study Setting, Data Collection, and Respondents}

The final self-administered questionnaire and cover letter were distributed and collected by a group of trained research assistants in family practice patient waiting rooms in 4 clinics in central Texas. Waiting room samples are often used in studies of this type, as they provide access to the appropriate population. ${ }^{40-42}$ The clinics are staffed by family physicians employed by a large multispecialty group practice that is academically affiliated with a university and a medical school. These are continuity clinics that provide routine chronic care and wellness care. Approximately 50\% of the appointments are for same-day acute medical problems. The 4 clinics were chosen because they serve a demographically diverse patient population and are relatively large, providing care to between 2,400 and 8,200 patients per month with 6 to 20 primary care physicians per clinic. In November 2005 data were collected for 8 full days at each of the clinics covering each weekday. No data were collected during night or weekend hours. All adult patients entering the waiting room were approached.

\section{Statistical Analysis}

Using the SAS statistical analysis software (SAS v9.1, SAS Institute, Cary, North Carolina), we selected a system of 4 equations to study the proposed relationships among the variables of interest (Figure 2). In this system, the variables adherence, commitment, and trust that appear as regressors in equations (1), (2), and (3) also appear as dependent variables in equations (2), (3), and (4), respectively. It is well established that estimating the above system of equations by ordinary least squares (OLS) analysis will yield inconsistent estimates ${ }^{43}$; furthermore, the errors across equations (1) through (4) may be correlated. As a result, consistent with literature in economics and marketing, ${ }^{44,45}$ we used a 3 -stage least squares (3SLS) procedure that accounts for the correlation across the error terms and thus yields consistent estimates. We conducted this analysis both with and without the relationship commitment variable. Finally, while analyzing the effect of the relationship variables on healthy eating behavior, we accounted for other control variables, such as the presence of a chronic illness and patient demographics (Figure 2).

\section{RESULTS}

\section{Respondents}

Approximately $75 \%$ of patients approached agreed to participate in the study. Questionnaires were collected from 1,008 patients; 869 patients' questionnaires were deemed complete and usable for the analysis. The majority of our respondents were female (66\%), college educated (72\% had at least some college), and white $(81 \%)$, and had incomes between $\$ 25,000$ and $\$ 75,000$ (74\%). The average age of the respondents was 50 years.

\section{Patient-Physician Relationship}

Table 2 displays the results of the 3SLS estimation for the system of equations (1) through (4). The proposed system of equations fits the data well, with the systemwide $R^{2}$ for the proposed set of equations equal to 0.71 . When we repeated the $3 \mathrm{SLS}$ without the relationship commitment variable, the systemwide $R^{2}$ decreased to 0.62 , empirically demonstrating the value of relationship commitment in understanding the patient-physician relationship.

\section{Influence of Trust and Commitment}

Specific results from our proposed model showed that all of the significant coefficients had the expected signs (Table 2). As expected, knowledge of the patient, competence, and autonomy support were significantly related to patient trust $(P<.001$ for all 3 variables). Both trust $(P<.001)$ and commitment $(P=.02)$ were positively associated with adherence. The results also supported the hypotheses of positive relationships between adherence and commitment $(P<.001)$ and between trust and commitment $(P<.001)$. In other

\section{Figure 2. System of 4 equations used to assess relationships among the variables of interest.}

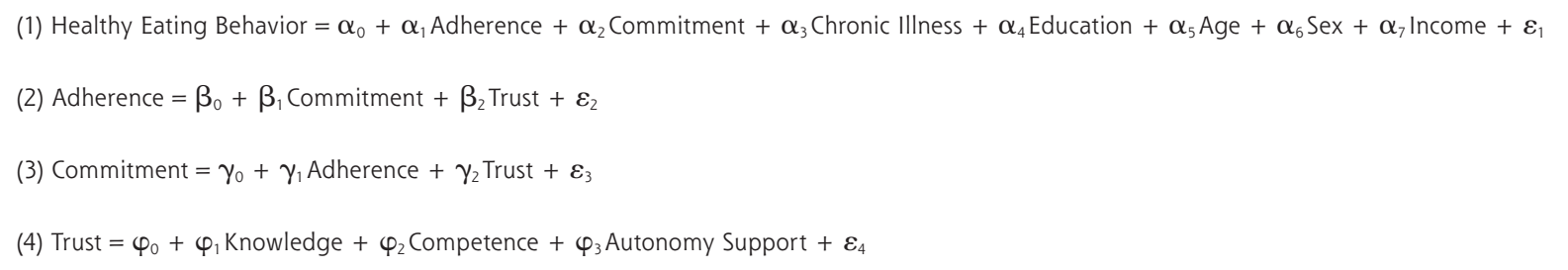


words, the greater patients' levels of adherence and trust, the greater their level of commitment to the physician. Additionally, the results supported our model by indicating that adherence $(P<.001)$ and commitment $(P<.001)$ are associated with healthy eating behavior.

\section{Influence of Control Variables}

With respect to the control variables, patients who were older $(P<.001)$, had higher incomes $(P=.047)$, and were more educated $(P=.01)$ had healthier eating patterns (Table 2). All other factors remaining the same, female patients had healthier eating behavior than their male counterparts $(P=.001)$. Higher education and income as well as female sex have been linked to healthier eating in previous research, with education being the most influential factor. ${ }^{46}$ We also controlled for chronic illness and found that it had no significant effect on eating behavior.

\section{DISCUSSION}

Most patients want a strong relationship with a primary doctor. ${ }^{1,21,47,48}$ The vulnerability and dependency inherent in being ill and at a knowledge disadvantage, the necessity of revealing personal information, and the sheer importance of the service make finding-and keeping - a "good doctor" a consumer priority. Literature converges on patients' valuing relationships with physicians who evoke trust and convey respect. Physicians evoke patients' trust and convey respect by listening carefully to their patients, developing whole-person knowledge about them, explaining issues clearly and forthrightly, treating patients as partners in their own care, showing compassion, and being thorough. ${ }^{1,8,12,15,47,49-56}$

We designed our study to specifically include relationship commitment because its measurement should yield a richer understanding of the patient-physician relationship. Although trust is an essential component of relationship commitment, it is not its equivalent. Patients may trust their physicians but not necessarily feel strongly about continuing their relationship with them. Our measure of relationship commitment assesses the degree to which patients value the relationship and want it to continue.

Results for our sample show a significant association between the patientphysician relationship and patients' adherence to their physician's medi- cal recommendations and healthy eating behavior. Strength of the relationship matters. Patients' trust in the physician and commitment to the relationship offer a more complete understanding of the relationship. The patient-physician relationship is built not only from physicians' medical competence, but also from their interpersonal behavioral competence. If a "good doctor" is one who positively influences health-related behaviors, then our findings support the conclusion that good doctors are both interpersonally proficient and technically proficient, not just the latter. They know their patients and work with them in a spirit of partnership (conceptualized as autonomy in this study). Both knowledge of patients and support of their autonomy are consistent with conveying respect.

In a joint presentation at the 2006 Institute of Healthcare Improvement National Quality Forum, primary care physicians Douglas Eby, MD, and Charles Kilo, MD, argued that the real work of advancing health is physicians affecting the choices made by individuals with regard to eating, drinking, smoking, exercising, managing stress, parenting, taking prescribed medications, and other behaviors. Their position is supported by data-based estimates on the relative impact of 5 domains on US deaths: genetics, social circumstances, environmental conditions, behavioral choices, and medical care. ${ }^{57}$ While recognizing the interconnectedness of the categories, the research-

\begin{tabular}{|lccc|}
\hline \multicolumn{4}{l}{ Table 2. Estimates Derived With the System of Equations } \\
\hline Equation (Dependent Variable) & Coefficient & $t$ Statistic & $P$ Value \\
\hline Equation 1 (healthy eating behavior) & & & \\
Constant & 5.60 & 7.23 & $<.001$ \\
Adherence & 2.02 & 3.74 & $<.001$ \\
Commitment & 1.04 & 4.76 & $<.001$ \\
Presence of chronic illness & -0.28 & -1.20 & .23 \\
Education & 0.32 & 2.52 & .01 \\
Age & 0.03 & 4.57 & $<.001$ \\
Income & 0.16 & 1.98 & .047 \\
Sex & 0.72 & 3.25 & .001 \\
Equation 2 (adherence) & & & \\
Constant & 0.53 & 4.61 & $<.001$ \\
Commitment & 0.19 & 2.39 & .02 \\
Trust & 1.04 & 9.48 & $<.001$ \\
Equation 3 (commitment) & & & \\
Constant & 0.56 & 2.56 & .01 \\
Adherence & 1.48 & 9.26 & $<.001$ \\
Trust & 2.63 & 14.32 & $<.001$ \\
Equation 4 (trust) & & & \\
Constant & 0.17 & 4.25 & $<.001$ \\
Knowledge of patient & 0.14 & 6.87 & $<.001$ \\
Medical competence & 0.24 & 11.62 & $<.001$ \\
Autonomy support & 0.32 & 14.01 & $<.001$ \\
\hline Note: The system of equations was estimated using $3-$-stage least squares (35LS) analysis. \\
\hline
\end{tabular}


ers concluded that approximately $40 \%$ of deaths are caused by modifiable behavior patterns, such as poor diet, physical inactivity, substance abuse, and poor coping strategies for stress.

What is most intriguing about our findings is the influence that primary care physicians with strong patient relationships appear to have on their patients' behavior. Other research also suggests the positive influence that good physicians can have on patients' health-related behaviors. In another study, primary care visits characterized by higher levels of physician-patient concordance (as reported by physicians) were associated with one-third higher medication compliance. ${ }^{58}$ The Diabetes Prevention Program, a randomized controlled trial, found intensive lifestyle modification to be more effective than metformin for reducing the incidence of type 2 diabetes. ${ }^{59}$ Patient adherence to lifestyle recommendations (including healthy eating) was a central feature for successful interventions, and adherence was optimized when physicians developed a coaching approach to encourage patients to make positive choices and develop self-sufficiency and assist them in identifying and overcoming barriers. ${ }^{60}$ These interventions are most effective when physicians are part of a larger team of allied health professionals.

The conceptualization and measurement of relationship commitment in the present study may help explain the nature of physicians' influence on their patients' behavior. Strong relationships require that both parties desire to maintain them. Relationships inevitably suffer and frequently end when one party does not reciprocate the investment of the other. One possible interpretation of our findings is of patients investing in the quality of a valued relationship with their physician through positive, healthy behavior.

To invest in stronger patient relationships while managing the pressures of time, physicians need to consider and develop new approaches to educate patients. Needed are methods or processes that make counseling and education more available to patients and more practical for physicians to provide from both time and financial standpoints. For example, physicians could schedule group educational appointments, create physician and nonphysician teams, and seek more progressive health insurance plans that reimburse preventive and education services. ${ }^{61,62}$

We can draw conclusions from this study about our sample-but not about a broader group of patients because of sampling limitations. Our data come from patients in 4 clinics of a single regional health care organization. A larger, geographically dispersed sample could reveal important regional differences. Our respondents were largely white and relatively well edu- cated; a more demographically diverse sample could reveal salient differences, as could a sample of patients less established with primary care physicians. Also, we studied patients' relationship with their primary care physicians and cannot claim that our findings apply to other types of physicians; moreover, patients' relationships with clinicians other than their primary care physicians may have played a role in the outcomes we report. Waiting room samples offer the advantages of access to respondents and good participation rates, but have the disadvantage of favoring patients who make frequent appointments. Only patients visiting the clinics during the 8-day data collection period had an opportunity to participate in the study.

Our study's design creates the possibility of selfreport bias. In particular, the adherence and healthy eating behavior constructs may be subject to socially desirable responses, leading participants to underestimate or overestimate their responses. Even so, literature suggests that self-reported measures are useful for developing hypotheses and in initial investigations. ${ }^{63,64}$ Some studies suggest that the response bias that occurs from self-reported measures is not a grave concern when this bias does not vary systematically. ${ }^{65,66}$ Given the focus of this research, we do not believe that any self-reporting bias that exists will affect the substantive findings or vary systematically, but we recognize it as a potential threat to validity. The addition of objective measures, however, especially of the adherence and healthy eating behavior constructs, could help solidify the validity of findings. A social desirability bias scale could also be incorporated in future research. As an example, the Crowne-Marlowe Scale ${ }^{67}$ helps researchers establish discriminant validity by comparing intercorrelations between the social desirability scale and other scales of interest. ${ }^{68}$

Additional research is needed to both replicate and extend our findings. Future study could include other patient behaviors, the application of the model to different types of physicians, and possible changes among associations of model variables over time. Also, our study focuses on the patient-physician relationship from the patient's perspective. Research that simultaneously assesses patient and physician commitment to the relationship could be useful.

The patient-physician relationship is central to the delivery of high-quality health care. Relationship commitment is a construct that merits further research. Continued research on what contributes to and detracts from strong patient-physician relationships should help clinicians craft improved practice strategies and lead to healthier patients.

To read or post commentaries in response to this article, see it online at http://www.annfammed.org/cgi/content/full/6/1/6. 
Key words: Physician-patient relations; relationship commitment; trust; physician behavior; patient adherence; patient compliance; healthy eating behavior; primary care

Submitted January 26, 2007; submitted, revised, July 13, 2007; accepted July 31, 2007

Funding support: This work was supported by Scott $\&$ White, Texas AEM University.

\section{References}

1. Safran DG. Defining the future of primary care: what can we learn from patients? Ann Intern Med. 2003;138(3):248-255.

2. Aiken LH, Lewis CE, Craig J, Mendenhall RC, Blendon RJ, Rogers $\mathrm{DE}$. The contribution of specialists to the delivery of primary care. N Engl J Med. 1979;300(24):1363-1370.

3. Agency for Health Care Policy and Research, and Center for Cost and Financing Studies. 1987 NMES Household Survey and Health Insurance Plans Survey Data [CD-ROM]. Rockville, MD: Agency for Health Care Policy and Research; 1998. AHCPR publication 98-DP02.

4. Davis JA, Smith TW. The NORC General Social Survey: A User's Guide. Newbury Park, CA: Sage Publications; 1992.

5. Weinick RM, Drilea SK. Usual sources of health care and barriers to care, 1996. Stat Bull Metrop Insur Co. 1998;79(1):11-17.

6. Fan VS, Burman M, McDonell MB, Fihn SD. Continuity of care and other determinants of patient satisfaction with primary care. J Gen Intern Med. 2005;20(3):226-233.

7. Atlas SJ, Chang Y, Lasko TA, Chueh HC, Grant RW, Barry MJ. Is this "my" patient? Development and validation of a predictive model to link patients to primary care providers. J Gen Intern Med. 2006;21(9):973-978

8. Baker R, Mainous AG III, Gray DP, Love MM. Exploration of the relationship between continuity, trust in regular doctors and patient satisfaction with consultations with family doctors. Scand J Prim Health Care. 2003;21(1):27-32.

9. Bendapudi N, Berry LL. Customers' motivations for maintaining relationships with service providers. J Retailing. 1997;73(1):15-37.

10. Mechanic $D$, Schlesinger $M$. The impact of managed care on patients' trust in medical care and their physicians. JAMA. 1996;275(21):1693-1697.

11. Leopold N, Cooper J, Clancy C. Sustained partnership in primary care. J Fam Pract. 1996;42(2):129-137

12. Thom DH, Campbell B. Patient-physician trust: an exploratory study. J Fam Pract. 1997;44(2):169-176.

13. Doney PM, Cannon JP. An examination of the nature of trust in buyer-seller relationships. J Marketing. 1997;61(2):35-51.

14. Fugelli P. Trust-in general practice. Br J Gen Pract. 2001;51(468): 575-579.

15. Safran DG, Taira DA, Rogers WH, Kosinski M, Ware JE, Tarlov AR. Linking primary care performance to outcomes of care. J Fam Pract. 1998;47(468):213-220.

16. Hopfield J, Linden RM, Tevelow BJ. Getting patients to take their medicine: improving adherence to drug regimens can save lives and reduce health care costs. McKinsey Q. December 2006. http:// www.mckinseyquarterly.com/article_page.aspx?ar $=1872 \varepsilon 12=12 \varepsilon 13$ $=62 \varepsilon$ srid $=17 \varepsilon g p=0 \#$ foot 1 . Accessed December 18, 2006 .

17. Franks $P$, Fiscella $K$, Shields CG, et al. Are patients' ratings of their physicians related to health outcomes? Ann Fam Med. 2005;3(3): 229-234.

18. Morgan RM, Hunt SD. The commitment-trust theory of relationship marketing. J Marketing. 1994;58(3):20-38.
19. Demmer C. Relationship with health care provider and adherence to HIV medications. Psychol Rep. 2003;93(2):494-496.

20. DiMatteo MR, Sherbourne CD, Hays RD, et al. Physicians' characteristics influence patients' adherence to medical treatment: results from the Medical Outcomes Study. Health Psychol. 1993;12(2):93-102.

21. Love MM, Mainous AG III, Talbert JC, Hager GL. Continuity of care and the physician-patient relationship: the importance of continuity for adult patients with asthma. J Fam Pract. 2000;49(11):998-1004.

22. Donaldson MS, Yordy KD, Lohr K, Vanselow NA, eds. Primary Care: America's Health in a New Era. Washington, DC: National Academy Press; 1996.

23. Jayanti RK, Burns AC. The antecedents of preventive health care behavior: an empirical study. J Acad Market Sci. 1998;26(1):6-15.

24. DiMatteo MR, Giordani PJ, Lepper HS, Croghan TW. Patient adherence and medical treatment outcomes: a meta-analysis. Med Care. 2002;40(9):794-811.

25. Haynes RB. Determinants of compliance: the disease and the mechanisms of treatment. In: Haynes RB, Taylor DW, Sackett DL, eds. Compliance in Health Care. Baltimore, MD: Johns Hopkins University Press; 1979:49-62.

26. Miller NH, Hill M, Kottke T, Ockene IS. The multilevel compliance challenge: recommendations for a call to action. A statement for healthcare professionals. Circulation. 1997;95(4):1085-1090.

27. Burke LE, Dunbar-Jacob JM, Hill MN. Compliance with cardiovascular disease prevention strategies: a review of the research. Ann Behav Med. 1997;19(3):239-263.

28. McDonald HP, Garg AX, Haynes BR. Interventions to enhance patient adherence to medication prescriptions: scientific review. JAMA. 2002;288(22):2868-2879.

29. Olshansky SJ, Passaro DJ, Hershow RC, et al. A potential decline in life expectancy in the United States in the 21st century. $N$ Engl J Med. 2005;352(11):1138-1145.

30. Manson JE, Skerrett PJ, Greenland P, Vanltallie TB. The escalating pandemics of obesity and sedentary lifestyles. A call to action for clinicians. Arch Intern Med. 2004;164(3):249-258.

31. Valdes AM, Andrew T, Gardner JP, et al. Obesity, cigarette smoking and telomere length in women. Lancet. 2005;366(9486):662-664.

32. Whitmer RA, Gunderson EP, Barrett-Connor E, Quesenberry CP Jr, Yaffe K. Obesity in middle age and future risk of dementia: a 27 year longitudinal population based study. BMJ. 2005;330(7504):1360.

33. Kaplan JP, Livermon CT, Krook VL, eds. Preventing Childhood Obesity: Health in the Balance. Washington, DC: The National Academies Press; 2005.

34. Stewart MA. Effective physician-patient communication and health outcomes: a review. CMAJ. 1995;152(9):1423-1433.

35. Larson EB, Yao X. Clinical empathy as emotional labor in the patient-physician relationship. JAMA. 2005;293(9):1100-1106.

36. Coulter KS, Coulter RA. Determinants of trust in a service provider: the moderating role of length of relationship. J Serv Mark. 2002;16(1):35-50.

37. Ware JE, Snyder MK, Wright WR, Davies AR. Defining and measuring patient satisfaction with medical care. Eval Program Plann. 1984;6:247-263.

38. Safran DG, Kosinski M, Tarlov AR, et al. The Primary Care Assessment Survey: tests of data quality and measurement performance. Med Care. 1998;36(5):728-739.

39. Glasgow RE, Ory MG, Klesges LM, Cifuentes M, Fernald DH, Green LA. Practical and relevant self-report measures of patient health behaviors for primary care research. Ann Fam Med. 2005;3(1):73-81.

40. Kahn BE, Luce MF. Understanding high-stakes consumer decisions: mammography adherence following false-alarm test results. Marketing Sci. 2003;22(Summer):393-410. 
41. Little P, Everitt H, Williamson I, et al. Preferences of patients for patient centred approach to consultation in primary care: observational study. BMJ. 2001;322(7284):468-472.

42. Potter MB, Vu JD, Croughan-Minihane M. Weight management: what patients want from their primary care physicians. J Fam Pract. 2001;50(6):513-518.

43. Judge G, Hill R, Lee T. The Theory and Practice of Ecometrics. New York, NY: Wiley; 1985.

44. Zellner $A$, Theil $H$. Three stage least squares: simultaneous estimation of simultaneous equations. Econometrica. 1962;30(1):54-78.

45. Bayus BL, Putsis WP Jr. Product proliferation: an empirical analysis of product line determinants and market outcomes. Marketing Sci. 1999;18(2):137-153

46. Popkin BM, Zizza C, Siega Riz AM. Who is leading the change? U.S. dietary quality comparison between 1965 and 1996. Am J Prev Med. 2003;25(1):1-8.

47. Mainous AG III, Baker R, Love MM, et al. Continuity of care and trust in one's physician: evidence from primary care in the United States and the United Kingdom. Fam Med. 2001;33(1):22-27.

48. Nutting PA, Goodwin MA, Flocke SA, et al. Continuity of primary care: to whom does it matter and when? Ann Fam Med. 2003;1(1): 149-155.

49. Tarrant C, Stokes T, Baker R. Factors associated with patients' trust in their general practitioner: a cross-sectional survey. Br J Gen Pract. 2003;53(495):798-800.

50. Emanuel EJ, Dubler NN. Preserving the physician-patient relationship in the era of managed care. JAMA. 1995;273(4):323-329.

51. Martin JC, Avant RF, Bowman MA, et al. The Future of Family Medicine: a collaborative project of the family medicine community. Ann Fam Med. 2004;2(Suppl 1):S3-S32.

52. Wright EB, Holcombe C, Salmon P. Doctors' communication of trust, care, and respect in breast cancer: qualitative study. BMJ. 2004;328(7444):864.

53. Bright B. Health poll: patients on doctors. Wall Street Journal. October 11, 2004:2.

54. Saultz JW, Albedaiwi W. Interpersonal continuity of care and patient satisfaction: a critical review. Ann Fam Med. 2004;2(5):445-451.

55. Borrell-Carrio F, Suchman AL, Epstein RM. The biopsychosocial model 25 years later: principles, practice, and scientific inquiry. Ann Fam Med. 2004;2(6):576-582.
56. Bendapudi NM, Berry LL, Frey KA, Parish JT, Rayburn WL. Patients' perspectives of ideal physician behaviors. Mayo Clin Proc. 2006;81(3):338-344.

57. McGinnis MJ, Williams-Russo P, Knickman JR. The case for more active policy attention to health promotion. Health Aff (Millwood). 2002;21(2):78-93.

58. Kerse N, Buetow S, Mainous AG III, Young G, Coster G, Arroll B. Physician/patient relationship and medication compliance: a primary care investigation. Ann Fam Med. 2004;2(5):455-461.

59. Knowler WC, Barrett-Connor E, Fowler SE, et al. Reduction in the incidence of type 2 diabetes with lifestyle intervention or metformin. N Engl J Med. 2002;346(6):393-403.

60. Koenigsberg MR, Bartlett D, Cramer JS. Facilitating treatment adherence with lifestyle changes in diabetes. Am Fam Physician. 2004;69(2):309-316.

61. Berry LL, Seiders K, Wilder SS. Innovations in access to care: a patient-centered approach. Ann Intern Med. 2003;139(7):568-574.

62. Berry LL, Mirabito AM, Williams S, Davidoff F. A physicians' agenda for partnering with employers and insurers: fresh ideas. Mayo Clin Proc. 2006;81(12):1592-1602.

63. Spector PE. Using self-report questionnaires in OB research: a comment on the use of a controversial method. J Organ Behav. 1994;15:385-392.

64. Shanafelt TD, Bradley KA, Wipf JE, Back AL. Burnout and selfreported patient care in an internal medicine residency program. Ann Intern Med. 2002;136(5):358-367.

65. Mittal V, Kamakura WA. Satisfaction, repurchase intent, and repurchase behavior: investigating the moderating effects of customer characteristics. J Marketing Res. 2001;38(1):131-142.

66. Griffin A, Hauser JR. Patterns of communication among marketing, engineering and manufacturing - a comparison between two new product teams. Manage Sci. 1992;38(3):360-373.

67. Crowne DP, Marlowe D. The Approval Motive: Studies in Evaluative Dependence. New York, NY: Wiley; 1964.

68. King MF, Bruner GC. Social desirability bias: a neglected aspect of validity testing. Psychol Mark. 2000;17(2):79-103. 